\title{
Improving an online STEM Course through Quality Matters Certification - A Case Study
}

\section{Dr. Hong Wang, University of Toledo}

Dr. Hong Wang is an Associate Professor in Computer Science and Engineering Technology program in the Department of Engineering Technology in the University of Toledo. He received his M.A and Ph.D in Computer Science from Kent State University (Kent, OH, USA). His research has covered parallel system design, smart building design, unmanned vehicle navigation under GPS denied environment and secure robot communications. His recent research interests are in data science field and STEM education. 


\title{
Improving an online STEM course through Quality Matters Certification - A case study
}

\begin{abstract}
Online STEM teaching is challenging in many ways such as instructor student interaction, clarity in expectations or effectiveness in content delivery. As an effort to better understand and find possible solutions to these issues, the author applied for Quality Matters (QM) certification for a database systems course to improve online course quality. In the process of trying to obtain QM certification, the author was not only able to improve the look and feel of the online course but more importantly, also improved online course content as a result of applying QM rubrics and standards. The objectives in the course also support objectives created in the department for ABET accreditation. This paper describes how QM certification helped the instructor to setup an easy to use blackboard site, clear objectives, grading rubrics and assessment methods. Specific module improvements presented in this paper includes teaching software tools, video tutorials that support course objectives and grading rubrics. Comparative study results are presented showing significant learning outcome improvements. The paper aims to offer a new angle for educators to look for ways to improve STEM online teaching.
\end{abstract}

\section{Introduction}

Online student enrolment in the past decade has been increasing steadily. Part of the reasons of this growth is that online teaching format appeals to non-traditional students who may have timedemanding occupations or long distance traveling to the academic campus $[1,2]$. In the recent years, educators found that high quality online education could be obtained if adopting appropriate standards. Quality Matters (QM) is such an effort with tremendous success.

The Computer Science and Engineering Technology Program (CSET) in the University of Toledo is an ABET Computing Accreditation Committee (CAC) accredited computer science program. A large portion of the enrolled students in the program is non-traditional. The CSET program has been using online courses for more than 10 years. During this period, online teaching platforms have undergone drastic transformation. A lot of technological advances have made many teaching methods possible such as hosting large video files in the cloud. To better utilize these technologies, online classrooms need to be organized effectively. QM standards are specifically created to help instructors to achieve this goal. Adopting QM standards could help educators to structure the online classroom to better service the online student population.

The author started applying for QM certification for the course Database-Driven Website in spring 2017 and obtained national QM certification in summer 2017. The initial purpose was to better structure the online course based on great reviews reporting experiences and positive student responses to the QM qualified courses [3]. To the author's surprise, the QM transformation turned out to be also helpful with the class content development. The author also found that the process helped the author to discover improvement opportunities for certain 
teaching contents. In this paper, the author describes the effects that QM application process had on teaching content development. One particularly helpful feature was course and module objectives. The author found that they are aligned with program objectives and ABET outcomes and could help ABET assessment process making overall teaching learning objectives consistent.

This paper selected some major topics that the author found most helpful. These topics show how applying design standards helped course contents development, student learning experience, and ABET accreditation effort.

\section{QM Standards and Course Content Development}

This course teaches database system design concepts followed by SQL queries. Theoretical database models were developed during the designing period. After practicing SQL query language, students practice on developing a database on the server side. The server-side programming language PHP is used to access the database producing a dynamic database driven website. Many practical skills are involved in the course project development. Delivering the skillset effectively over the online format poses challenges to the instructor.

Before QM was applied, the course used traditional syllabus for online teaching which covers the following contents: Instructor's name, course offering date period, material covered, assignment and test information, grading information, late policy and plagiarism policy. Since students are not directly in contact with the instructor in online courses, a more thorough instructor's description could help to improve students' relationship with the instructor. QM requires a much thorough introduction including a bio of the instructor, direction of where to find information, communication methods and more. In Blackboard menu, "Start Here" tab is very suitable for accomplishing this purpose. Initially, this tab contained a summary of the course content. After modification following QM standards, "Start Here" tab serves as a guided tour through the entire course. When developing this guide, the instructor found that the course menu items could be organized more efficiently. A well-organized menu could help students find relevant content easily and have an overall pleasant experience. Dividers are used to group the menu to a few sections including a "Course News" and "Start Here" section, a course content section, a communication section and a support resources section. These sections contain the traditional tabs necessary for students to find the syllabus, study the content, do assignment and check grades etc. After examining QM standards, the instructor added a few more tabs. To give students a clear idea on course objectives, a "Course Objective" tab was added. For the students to refer to the grading rubrics conveniently, a "Rubric" tab was added. All these modifications following QM standards make the course menu easier to follow and information easier to be found.

The course contents were initially organized by putting all the text and video tutorials into a single "course content" content area with no clear objectives associated with the individual tutorials. The course objectives were only described in the course syllabus. Following this 
original design, students may be lost on how the learning activities fit into the course objectives that need to be accomplished.

QM requires that the relationship between the learning activity and learning objectives clearly defined. Although the course objectives were defined in the syllabus, students may get lost when going through the tutorial contents one at a time. As example, the students need to understand that $\mathrm{E} / \mathrm{R}$ (Entity/Relationship) diagram is a modeling method that ties to the course objective. It is much clearer if the learning activity could include sub-objectives that ties back to the course objectives.

Initially, the course used a "Schedule" page to guide learning activities throughout the semester. The teaching contents were grouped together as one big module. To adopt clear sub-objectives, multiple course sub-modules are needed. Students may learn from sub-modules each week with sub-objectives that are mapped to course objectives. Weekly modules are setup to help students to progress from database modeling to practical SQL applications and eventually to building more complicated web projects. Students could make informed improvement during the process.

The objectives of each weekly module are clearly stated in the beginning of each module and mapped to the course objectives. This gives students a clear idea on how this module is going to help them achieve the overall course objectives.

During module development process, it was discovered that one class module on parallel database topic was not mapped to any course objectives. An additional course objective was later created. Because this course content was not in the original course objectives in course description, it was not integrated to ABET outcomes assessment rubrics. The program may consider it as one of the assessment outcomes in the future. Another discovery was that teaching material developed for the modules were not balanced. Certain modules needed more coverage with additional videos or text tutorials. QM standard recommends a variety of instructional material being used in the course. In addition to the two text books used for the course, the instructor supplemented the course with PowerPoint slides and video tutorials. As an alternative instructing method, video tutorial can incorporate graphical demonstration with vocal instructions. This approach is more advantageous than text instructional material in technological teaching.

Since Blackboard has limited storage space, the large number of videos made by the author quickly filled up the allocated space. To accommodate the newly developed videos, the author chose to use Echo360 [4]. Echo360 may also be integrated with Blackboard course modules to monitor student performance. With this integration, the instructor could track student video watching activities. Students could get timely feedback if low performance was due to the lack of video watching activities. A screen capture of such a video is shown in figure 1. 


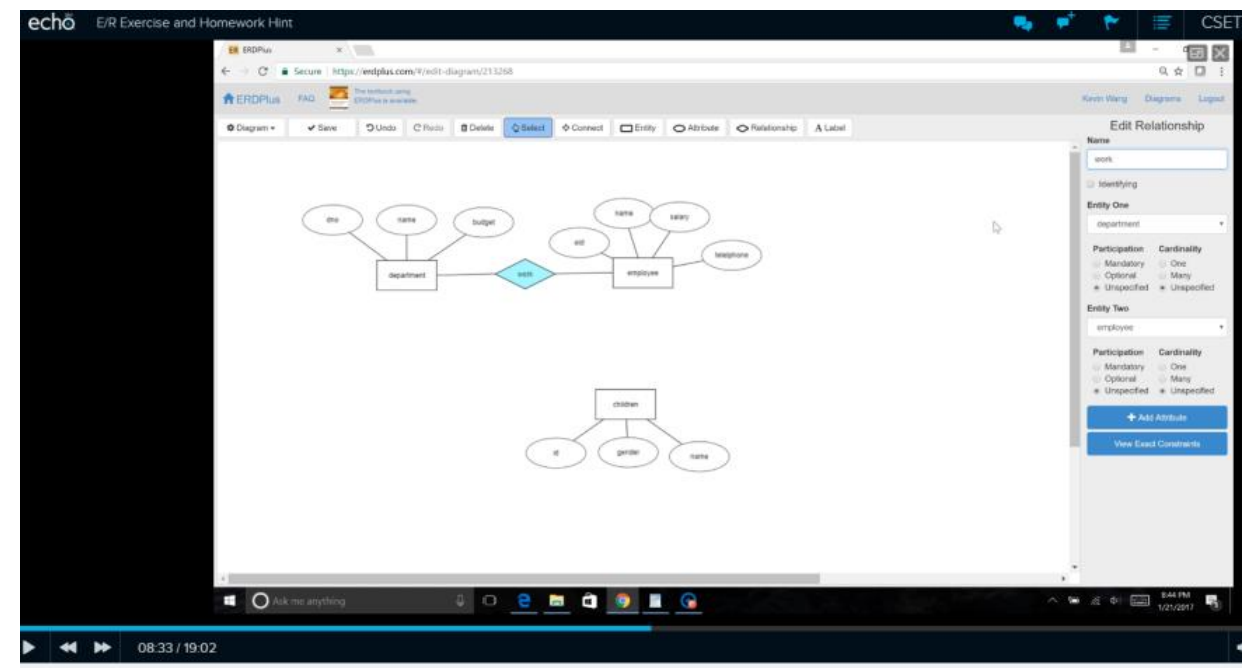

Figure 1. A screen capture of a video lecture on $\mathbf{E} / \mathbf{R}$ diagram

Throughout the semester, students may exhibit difficulty in understanding certain material and contact the instructor with questions. The instructor could make additional videos or improve the existing ones to address the questions or concerns. The instructor student interactivity could be more efficient than repeatedly tutor each individual student separately with the same concerns.

This objective-driven course development process has revealed the parts of the course that need more development. It also helped the author to avoid over-development on the topics that already had enough teaching material for the related objectives.

\section{Assessment}

Assignments were initially grouped together under an "Assignment" tab. The assignment and objective alignment was not emphasized. After adopting QM standards, a link to the assignment assessing the outcome of the sub-objective was added to each module. Students were given a better guide on what is being assessed and where to find the teaching material relevant to the assignments. While mapping the assignments to modules, the instructor found that more material need to be developed to help with some of the assignments. This motivates the instructor to create additional video tutorials. In some cases, new software tools were adopted to increase the student's efficiency. Further analysis of students' work on the assignments reveals that better tools could be incorporated into the course to improve learning outcomes. As example, erdplus.com [5] was used for E/R diagram development, MySQL Workbench [6] tool was adopted for UML development and filldb.info [7] was introduced for students to generate random data.

One of the strength of this course is to give students hands-on experience. Students going through the course are expected to be equipped with theoretical background and be good at practical database system development. Practical exercises in turn could enhance students' understanding of theoretical foundation. Various tools are used to improve students' system 
development skills. Using the tools students could avoid trivial system setup time and focus on technologies that are more closely related to the material taught. One of the assignments was to setup a database that is filled with data. The data are then displayed on a website after PHP processing. The database in use is the main thread connecting all the assignments in the course. The students design the E/R and UML models of the database in the beginning, and then learn SQL to implement and query the database on MySQL. Filling data manually could have been tedious, time-consuming and could distract students from Database design concepts. Filldb.info is a website that takes "Create Table" statements written by the students as input and automatically generates hundreds of rows of random data to fill the databases. Although there are many similar websites, filldb.info is the only one found enforcing referential integrity rules in the "Create Table" statements.

A nice feature in Blackboard is the support of Rubrics design. Before adopting QM, the instructor was not aware of the rubrics tool. The instructor's feedbacks on student's homework assignments are critical with the students' continuous improvement. A detailed grading rubric has at least two benefits. It informs the students the expectation of the homework assignment. After the students finished the assignment, grading rubrics could supply students with information on their strength and weaknesses before going to the next teaching module. QM require "Specific and descriptive criteria are provided for the evaluation of learners' work and are tied to the course grading policy" [8]. The blackboard grading rubrics is versatile in functionality. Detailed feedback may be given in supplied rubrics boxes. The assigned points to each scoring rubrics are then summed up automatically as the assignment grade. It was convenient for the instructor to further improve the assignment requirements to clarify homework expectations. The author received less student questions concerning assignment grading after adopting QM standards and making improvement on grading rubrics. An example of the rubrics is shown in Figure 2.

\begin{tabular}{|c|c|c|c|}
\hline & Unsatisfactory & Competent & Excellent \\
\hline Formatting & $\begin{array}{l}0(0 \%) \text { - } 0(0 \%) \\
\text { The Diagram components } \\
\text { are not in correct format, } \\
\text { e.g. Diamond, Rectangle. }\end{array}$ & $\begin{array}{l}1(4 \%)-4(16 \%) \\
\text { The Diagram components } \\
\text { are partially correct in } \\
\text { format, e.g. Diamond, } \\
\text { Rectangle. }\end{array}$ & $\begin{array}{l}5(20 \%) \text { - } 5(20 \%) \\
\text { The Diagram components } \\
\text { are in correct format, e.g. } \\
\text { Diamond, Rectangle. }\end{array}$ \\
\hline Specifications & $\begin{array}{l}0(0 \%)-2(8 \%) \\
\text { The diagram is mostly } \\
\text { incorrect on required entity } \\
\text { sets, attributes and } \\
\text { relationships. }\end{array}$ & $\begin{array}{l}3(12 \%) \text { - } 14 \text { ( } 56 \%) \\
\text { The diagram is partially } \\
\text { correct on required entity } \\
\text { sets, attributes and } \\
\text { relationships. }\end{array}$ & $\begin{array}{l}15(60 \%) \text { - } 15(60 \%) \\
\text { The diagram includes all } \\
\text { the required entity } \\
\text { sets, attributes and } \\
\text { relationships correctly. }\end{array}$ \\
\hline Multiplicity & $\begin{array}{l}0(0 \%)-0(0 \%) \\
\text { The diagram doesn't show } \\
\text { any correct multiplicity of } \\
\text { the relationships of the } \\
\text { entity sets. }\end{array}$ & $\begin{array}{l}1(4 \%) \text { - } 4(16 \%) \\
\text { The diagram defines and } \\
\text { shows some of the } \\
\text { multiplicities of the } \\
\text { relationships of the entity } \\
\text { sets correctly. }\end{array}$ & $\begin{array}{l}5(20 \%)-5(20 \%) \\
\text { The diagram defines and } \\
\text { shows multiplicities of the } \\
\text { relationships of the entity } \\
\text { sets correctly. }\end{array}$ \\
\hline
\end{tabular}

Figure 2. Example Grading Rubrics for the E/R Diagram Assignment 
When designing rubrics to assess if an objective has been met, the instructor needs to make sure that the objectives are assessable. The instructor could make assessable objectives or design creative methods to assess the objectives. As example, to evaluate whether the student can access the class server, a screen capture of the login page and a link to the page need to be submitted for grading.

\section{ABET Outcome Assessment Alignment}

Since CSET is ABET CAC accredited, this course needs to demonstrate that students could achieve specified ABET student outcomes. This should be done annually. The assessment document eventually maps to specific assignment grade data. However, the mapping from the assignment to the ABET criteria can be hard to track. The mechanism setup for the course objectives may serve the assessment effort smoothly. First, the ABET outcomes can be mapped to course objectives. As described in the previous sections, course objectives are mapped to module objectives which in turn are assessed by the corresponding assignments or exams. Three program outcomes were assigned to this course and the alignment is shown in table 1.

\section{Table 1. Objectives and Assessment Method Alignment}

\begin{tabular}{|c|c|c|}
\hline CAC outcomes & Course Objectives & Coverage and Assessment \\
\hline $\begin{array}{l}\text { a. An ability to select and } \\
\text { apply knowledge of } \\
\text { computing and mathematics } \\
\text { appropriate to the discipline. } \\
\text { More specifically, an ability } \\
\text { to apply mathematical } \\
\text { foundations, algorithmic } \\
\text { principles, and computer } \\
\text { science theory in the } \\
\text { modeling and design of } \\
\text { computer-based systems in a } \\
\text { way that demonstrates } \\
\text { comprehension of the } \\
\text { tradeoffs involved in design } \\
\text { choices }\end{array}$ & $\begin{array}{l}\text { Design relational database } \\
\text { models that demonstrate an } \\
\text { understanding of relational } \\
\text { database concepts and design } \\
\text { principles }\end{array}$ & $\begin{array}{l}\text { Covered by weekly modules } 1,2 \\
\text { and } 3 \text { and assessed by } \\
\text { assignment } 1\end{array}$ \\
\hline $\begin{array}{l}\text { c. An ability to design, } \\
\text { implement and evaluate a } \\
\text { computer-based system, } \\
\text { process, component, or } \\
\text { program to meet desired } \\
\text { needs and an ability to apply } \\
\text { design and development } \\
\text { principles in the construction } \\
\text { of software systems of } \\
\text { varying complexity }\end{array}$ & $\begin{array}{l}\text { Apply PHP server-side scripting } \\
\text { language and MySQL database } \\
\text { management system to the } \\
\text { creation of dynamic web site } \\
\text { applications }\end{array}$ & $\begin{array}{l}\text { Covered by weekly modules } 8, \\
10,11 \text { and } 12 \text { and assessed by } \\
\text { assignment } 5\end{array}$ \\
\hline $\begin{array}{l}\text { i. An ability to select and } \\
\text { apply current techniques, } \\
\text { skills, and tools necessary } \\
\text { for computing practice. }\end{array}$ & $\begin{array}{l}\text { Implement complete relational } \\
\text { database system to support } \\
\text { dynamic web site using PHP as } \\
\text { server-side script. }\end{array}$ & $\begin{array}{l}\text { Covered by weekly modules } 13 \text {, } \\
14 \text { and } 15 \text { and assessed by } \\
\text { assignment } 6\end{array}$ \\
\hline
\end{tabular}


By adopting QM standards, the assessment process for the course could be made more straightforward facilitating future course development. Adaptation to ABET assessment criteria evolvement may become more robust.

\section{Assessment of Student performance}

The results of the course improvement may be assessed through student satisfaction survey $[9,10]$. This paper takes an outcome based approach. Similar evaluation approach was adopted by SJSU [11]. Student assignment grades were used as measurement of the effectiveness of the course as being used in ABET assessment. This method directly reflects the students'

performance in the course. By comparing this data between two semesters, the instructor may monitor the improvements of the student's performance. The assessment data are readily available since the author has generated the ABET course assessment forms as part of continuous course and program improvement efforts.

Although the course completed national QM certification in summer 2017, the development effort was implemented during the Spring 2017 semester. Most of the features eventually led to the QM certificate were available in the Spring 2017 online course. Weekly modules were created on weekly basis through the semester.

Table 2 uses the data the author created for ABET outcome assessment. The headers of the columns are modified to align with QM course objectives. The achievement of course objectives 1, 3 and 4 are compared between spring 2016 before the changes were made for QM certification and spring 2017 which is after the QM adoption.

Grading is scaled to 5-excellent to 1-poor. There were 25 students in the spring 2016 and 20 students in the spring 2017. The outcome averages for the assignments are listed in Table 2.

Table 2. Assignment Grade Average Comparison

\begin{tabular}{|l|c|c|c|}
\hline & \multicolumn{3}{|c|}{ Average Student Grade (1-5) } \\
\hline Semester & Objective 1 & Objective 3 & Objective 4 \\
\hline & Homework E/R diagram and UML & Homework 5 & Homework 6 \\
\hline Spring 2016 & 3.5 & 3.7 & 4.2 \\
\hline Spring 2017 & 4.5 & 4.6 & 4.6 \\
\hline
\end{tabular}

In addition to taking the average course grade, the assessment also counted the number of students whose grade are either good (3.5 - 4.5 points) or excellent (4.5-5.0 points). The percentage of this number to the total is compared in table 3 . 
Table 3. Percentage of students whose grades are better than 3.5

\begin{tabular}{|c|c|c|c|}
\hline & \multicolumn{3}{|c|}{ Percentage of number of students whose grades are better than 3.5 } \\
\hline Semester & Objective 1 & Objective 3 & Objective 4 \\
\hline & Homework E/R diagram and UML & Homework 5 & Homework 6 \\
\hline Spring 2016 & $73.08 \%$ & $90.00 \%$ & $80.00 \%$ \\
\hline Spring 2017 & $90.00 \%$ & $94.12 \%$ & $89.49 \%$ \\
\hline
\end{tabular}

The author observed significant student performance improvement based on the data analysis.

\section{Conclusion and Future Considerations}

Adopting QM standards helped the author to identify course improvement opportunities and helped the author to develop course content. Significant improvement in student performance has been observed in this computer sciences database design course after adopting QM criteria and making relevant improvements.

Following QM standards and applying for certification may seem to be a challenging task which involves many design works. The benefits however, are more than just cosmetic changes that make the online course easier to follow. The implementation process could reveal opportunities to improve online course contents and benefit course assessment procedure.

In rapidly evolving technological areas like computer science, the content of the courses need to be frequently updated. This poses some challenges. Existing videos needs to be edited to accommodate new contents. Better video editing software could be used for continuous video tutorial improvement. The design of the courses needs to be prepare for significant curriculum changes to minimize development efforts while maintaining quality. QM standards may help instructors to find improvement needs more easily and quickly respond to the needs through course content development.

\section{References:}

[1] 2016 Online Education Trends. Retrieved from http://www.bestcolleges.com/wpcontent/uploads/2016-trends-in-online-education.pdf

[2] M. Hannay, T. Newvine, "Perceptions of distance learning: A comparison of online and traditional learning." Journal of Online Learning and Teaching. 2. 1-11. 2006

[3] D. L. Finley "Using Quality Matters (QM) to Improve All Courses", Journal of Teaching and Learning with Technology, Vol. 1, No. 2, pp. 48 - 50, December 2012.

[4] URL https://echo360.com/

[5] URL https://erdplus.com/ 
[6] URL https://www.mysql.com/products/workbench/

[7] URL http://filldb.info/

[8] "Non-annotated Standards from the QM Higher Education Rubric, Fifth Edition". Retrieved from

https://www.qualitymatters.org/sites/default/files/PDFs/StandardsfromtheQMHigherEducationR ubric.pdf

[9] T. Salama, N. Lee, G. Fitzgerald, L. W. Lee, M. M. McCarthy, "Advancing Online Teaching at an On-Ground Institution by Assessing Technical and Humanities Online Courses", 2015 ASEE Annual Conference \& Exposition, Seattle, Washington. 10.18260/p.23502, June 2015.

[10] C. E. Goodson, S. L. Miertschin, B. L. Stewart, "Distance Delivery of Courses: What Components are Important to Students?" 2015 ASEE Annual Conference \& Exposition, June 2011.

[11] L. E. Sullivan-Green, R. Mathur, A. H. Feinstein, "Flipping STEM Classrooms Collaboratively Across Campuses in California" 2017 ASEE Annual Conference \& Exposition, Columbus, Ohio. June 2017. 